\title{
Study on the Water Supply and the Requirements, Yield, and Water Use Efficiency of Maize in Heilongjiang Province Based on the AquaCrop Model
}

\author{
Tangzhe Nie ${ }^{1}$, Yang Jiao ${ }^{1}$, Yi Tang ${ }^{1}$, Na Li ${ }^{1}$, Tianyi Wang ${ }^{1,2}$, Chong Du ${ }^{1, *}$, Zhongxue Zhang ${ }^{2,3}$, Tiecheng $\mathrm{Li}^{2,3}$, \\ Shijiang Zhu ${ }^{4}$, Zhongyi Sun ${ }^{5}$ and Fengrui Li ${ }^{6}$ \\ 1 School of Water Conservancy and Electric Power, Heilongjiang University, Harbin 150080, China; \\ 2019036@hlju.edu.cn (T.N.); jiaoyang0814@163.com (Y.J.); ty979794@163.com (Y.T.); \\ L17863523371@163.com (N.L.); wangtianyi7176@163.com (T.W.) \\ 2 School of Water Conservancy and Civil Engineering, Northeast Agricultural University, \\ Harbin 150030, China; zhangzhongxue@163.com (Z.Z.); litiecheng1212@126.com (T.L.) \\ 3 Key Laboratory of Agricultural Water Resource Use, Ministry of Agriculture, Harbin 150030, China \\ 4 College of Hydraulic and Environmental Engineering, China Three Gorges University, Yichang 443002, China; \\ zhusjiang@aliyun.com \\ 5 College of Ecology and Environment, Hainan University, Haikou 570208, China; gis.rs@hainanu.edu.cn \\ 6 Xingtai Hydrographic Survey and Research Center of Hebei Province, Xingtai 054000, China; \\ 2191532@s.hlju.edu.cn \\ * Correspondence: duchong@hlju.edu.cn; Tel.: +86-136-3366-1083
}

check for updates

Citation: Nie, T.; Jiao, Y.; Tang, Y.; Li, N.; Wang, T.; Du, C.; Zhang, Z.; Li, T.; Zhu, S.; Sun, Z.; et al. Study on the Water Supply and the Requirements, Yield, and Water Use Efficiency of Maize in Heilongjiang Province Based on the AquaCrop Model. Water 2021, 13, 2665. https://doi.org/ 10.3390/w13192665

Academic Editor: Junzeng Xu

Received: 23 July 2021

Accepted: 24 September 2021

Published: 27 September 2021

Publisher's Note: MDPI stays neutral with regard to jurisdictional claims in published maps and institutional affiliations.

Copyright: (C) 2021 by the authors. Licensee MDPI, Basel, Switzerland. This article is an open access article distributed under the terms and conditions of the Creative Commons Attribution (CC BY) license (https:// creativecommons.org/licenses/by/ $4.0 /)$.
Abstract: Agricultural irrigation depends heavily on freshwater resources. Under the context of increasingly severe water shortages, studying the relationship among crop water requirements $\left(E T_{c}\right)$, actual crop evapotranspiration $\left(E T_{a}\right)$, irrigation water requirements $\left(I_{r}\right)$, yield, and water use efficiency (WUE) would be beneficial to improve the agricultural application of irrigation water. Based on the daily data of 26 meteorological stations in Heilongjiang Province from 1960 to 2015, this study used the calibrated AquaCrop model to calculate the $E T_{c}, E T_{a}, I_{r}$, and yield of maize (Zea mays L.) in different hydrological years (extremely dry years, dry years, normal years, and wet years) along with WUE to evaluate the mass of yield produced per unit mass of crop evapotranspiration (ET) under rainfed and irrigated scenarios. The results showed that $E T_{c}$ and $E T_{a}$ decreased first and then increased from the west to the east during the four types of hydrological years. $I_{r}$ exhibited a decreasing trend from the west to the east. Compared with the irrigation scenario, the rainfed scenario's average yield only decreased by $2.18,0.55,0.03$, and 0.05 ton/ha, while the WUE increased by $0.32,0.4,0.33$, and $0.21 \mathrm{~kg} / \mathrm{m}^{3}$ in the extremely dry years, dry years, normal years, and wet years, respectively. The results indicated that in the normal and wet years, the WUE was high in the central regions, and irrigation did not significantly increase yield; further, we determined that irrigation should not be considered in these two hydrological years in Heilongjiang Province. In the extremely dry and dry years, irrigation was necessary because it increased the yield, even though the WUE decreased. This study provides a theoretical basis for studying the regional irrigation schedule in Heilongjiang Province.

Keywords: maize; AquaCrop model; crop water requirements $\left(E T_{c}\right)$; actual crop evapotranspiration $\left(E T_{a}\right)$; irrigation water requirements $\left(I_{r}\right)$; yield; water use efficiency (WUE); irrigation and rainfed scenario

\section{Introduction}

At present, the shortage of freshwater is regarded as one of the most critical global problems by scientists, policymakers, and even the general public [1]. According to an analysis of global water scarcity, two-thirds of the world's population will be affected by water scarcity in the next few decades. Water shortages in developing countries are 
also attributable to water distribution, poor management, and the inherent injustices and inequities of water distribution [2]. Agricultural water accounts for $70-75 \%$ of the total freshwater extracted. The available agricultural resources and the narrowing yield gaps of all crops play a crucial role in providing sufficient food for the rapidly growing global population [3]. According to Food and Agriculture Organization (FAO) projections, food production in irrigated areas will need to be increased by more than $50 \%$ by 2050 , but only a $10 \%$ increase in water withdrawal for agriculture will be possible [4]. In addition, the large amount of agricultural irrigation has led to a rapid decline in the groundwater level over the past 20 years [5]. Some areas have experienced severe land subsidence, salt intrusion near the coast, degradation of ecosystems, and deterioration of groundwater quality [5].

Promoting sustainable agriculture, increasing crop productivity, and ensuring the effective management of limited water resources are indispensable for increasing global food production [6]. Maize (Zea mays L.) is one of the most important global food sources, accounting for $30 \%$ of the world's total grain production $[7,8]$. As the world's population continues to grow, by 2050, maize yield needs to increase by $66 \%$ to meet global demands [9]. As one of the arid countries, China is also the second-largest maize-producing country. Arid and semi-arid regions in the north of China make up 30\% of the national land area but have less than $20 \%$ of total national available water resources because precipitation is low and evapotranspiration is high [10-12]. Using precipitation resources reasonably may become one of the fastest and most effective ways to alleviate water shortages and reduce unnecessary irrigation $[7,13]$. Moreover, numerous studies have shown a correlation between crop yields and water consumption in arid regions, as precipitation and crop adaptability directly impact the precipitation use efficiency of crops, thereby affecting crop yields [13-15]. In the north of China, droughts occur in maize growing stages frequently; in dry years, irrigation alleviates the reduction in maize production, while in wet years, precipitation meets maize water requirements [16]. Therefore, in order to explore the difference between maize under rainfed and irrigation scenarios, make full use of precipitation to reduce irrigation water requirements $\left(I_{r}\right)$, study on maize evapotranspiration $(E T)$ and yield may provide a basis for the regional balance on irrigation and rainfed.

As a significant component of the regional and global hydrological cycle, crop water requirements $\left(E T_{c}\right)$ play an essential role in evaluating related $I_{r}$ and crop water stress in agricultural ecosystems [17]. Exploring the relationship between $E T_{c}$ and $I_{r}$ will help maximize the use of rain resources and optimize the allocation of regional water resources. As precipitation directly affects the $E T_{c}$, actual crop evapotranspiration $\left(E T_{a}\right)$, and $I_{r}$ values of different crops, for maize, the precipitation in normal years and wet years can almost meet the $E T_{a}$, and irrigation is only required in dry years. However, irrigation significantly increases the wheat yield in semi-arid areas [18]. Irmak indicated that in maize growing season, there was an ununiform temporal distribution of precipitation, resulting in greater $E T_{c}$ or $E T_{a}$ losses. In these circumstances, full irrigation has a higher yield than rainfed [19]. In semi-arid China, irrigation could alleviate crop $E T_{a}$ losses which are caused by the uneven distribution of precipitation, and in a dry year, irrigation would be more efficient to crop growth than in a wet year, though irrigation appears valuable in a wet year [20]. The relationship among $E T_{c}, E T_{a}$, and $I_{r}$ varies depending on the crop, region, precipitation amounts, and distribution patterns, especially the changes in effective precipitation that affect $E T_{a}, E T_{c}$, and $I_{r}$ [21].

Water use efficiency (WUE) can be used to assess the relationship between water and crop yields. Many studies have used WUE to evaluate the practicality of irrigation management (rainfed, limited, or full irrigation). Crops in the northern Republic of Serbia are largely grown under rainfed conditions; due to the high variability of regional precipitation, and low crop yields are closely related to insufficient precipitation [22]. In Vojvodina, WUE was found to be higher during dry and normal years than during wet years. Moreover, lower WUE and higher yields were found for fully irrigated treatments compared to rainfed treatments [23]. In arid areas, to increase crop yields and WUE, irrigation at a fixed time 
is more effective than rainfed irrigation [24]. A previous study showed that crop WUE increased with an increase in irrigation until the additional irrigation no longer produced additional yield [25]. Moreover, because of differences in regional environmental conditions and seasonal precipitation fluctuations, irrigation may not improve WUE and yield continuously [26]. In eastern China, especially during dry years with little precipitation, rainfed farming provides insufficient water to crops, and irrigation is needed to reduce yield loss [27]. In the case of seasonal precipitation fluctuations and large inter-annual differences in precipitation, WUE provides a theoretical basis for regional water consumption and changes in the irrigation schedule under different circumstances.

The above factors underscore the need to identify irrigation patterns under rainfed and irrigated scenarios to maximize the utilization of available resources and improve productivity. However, due to time, funding, and resource constraints, it is not feasible to evaluate large combinations of various crop management options under field scenarios in many different regions and environmental contexts. To solve this issue, AquaCrop, as a fully tested, calibrated, and validated crop model, can be used to evaluate factors affecting maize yield and WUE [28]. López-Urrea et al. noted that AquaCrop correctly simulates the evolution of the harvest index, canopy cover (CC), $E T_{a}, E T_{c}$, yield, and aboveground biomass and is a better model than MOPECO for assessing the impact of a specific irrigation system on crops [29]. Nader Pirmoradian et al. found that AquaCrop can accurately simulate the $I_{r}$ of a crop in wet, normal, and dry years [30]. Heng et al. further concluded that FAO's AquaCrop is an excellent crop growth model for designing and evaluating water management plans and studying the soil types and sowing dates of crops under rainfed or irrigated scenarios. The model was found to correctly simulate ET and production, and the measured and simulated values of WUE showed a high degree of fit [27]. However, when this model is implemented for practical purposes, it is necessary to use field measurements from different climate regions to verify the model under watermanagement scenarios to ensure the model's accuracy, as well as its potential limitation. Therefore, it is necessary to carefully test, calibrate, and validate the model for specific locations when simulating crop yields [31].

Heilongjiang Province is one of the main grain-producing areas [32]. As the main food crop, maize is a widely planted crop, and its planting area is increasing year by year. As of 2016, the planting area of maize was $7.72 \times 10^{6} \mathrm{hm}^{2}$, accounting for $52.2 \%$ of the province's crop planting area, and its yield was $3.544 \times 10^{7} \mathrm{t}$, accounting for $56 \%$ of the province's grain [33]. The East Asian summer monsoon controls precipitation in Heilongjiang Province, where the $E T_{c}$ and irrigation are different over time and space [34]. Therefore, it is necessary to quantify the $E T_{c}$ and $I_{r}$ of maize, clarify the temporal and spatial changes and trends of $E T_{c}$ and $I_{r}$, and determine the irrigation management methods necessary for different places and hydrological years. This assessment will provide essential information for irrigation strategies and sustainable water management to adapt to climate change in the region.

The purposes of this study were to (1) quantify the $E T_{c}, E T_{a}, I_{r}$, and yield of maize over four hydrological years in Heilongjiang Province (from 1960 to 2015) using AquaCrop; (2) clarify the temporal and spatial distribution of $E T_{c}$ and $E T_{a}$ in the growing seasons of maize; (3) determine the temporal and spatial variations in yield and WUE under irrigation and rainfed scenarios; and (4) further reveal the effects of rainfed and irrigated scenarios on the $I_{r}$ and WUE of maize.

\section{Materials and Methods}

\subsection{Study Area}

This paper used the daily meteorological data from 26 stations in Heilongjiang Province from 1960 to 2015, including the maximum air temperature, minimum air temperature, average relative humidity, average wind speed, sunshine duration, precipitation, and longitude and latitude information of each station. All the above data were obtained from the China Meteorological Data Network (http://data.cma.cn, accessed on 22 July 
2021), and the $\mathrm{CO}_{2}$ data were obtained from the UK Greenhouse Gas Emissions database (https:/ / www.gov.uk, accessed on 22 July 2021). Figure 1 shows the study area and the distribution of the site. Due to the different geographical locations of the meteorological stations in Heilongjiang Province, each station's division of annual accumulated temperature is different. According to the Heilongjiang Provincial Agricultural Commission's reports, "Heilongjiang Crop Variation Accumulative Temperature Zone" [35] and "Area Layout Planning of High-quality and High-yield Main Food Crops in Heilongjiang Province in 2015" [36], the sixth accumulative temperature zone is not suitable for maize planting. Therefore, the sixth temperature accumulation zone was not studied in this paper.

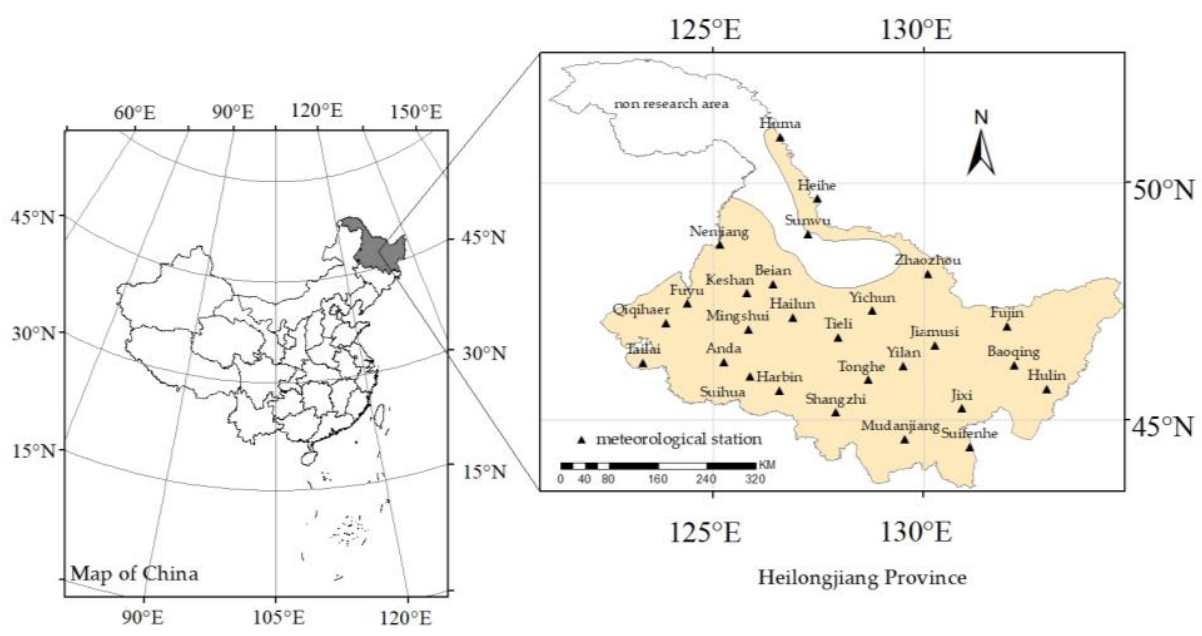

Figure 1. Map of the study area and distribution of meteorological stations in Heilongjiang Province.

\subsection{Sources of Experimental Data}

Data from three field experiments investigating maize planted in Heilongjiang Province, China, were used for the model calibration and verification (Table 1). The first experimental area was located at the Heilongjiang Province Hydraulic Research Institute, Harbin. The areas used for the second and third experiments were located at the Institute of Water Resources Science and Agricultural Technology Extension Center, Zhaozhou County, Daqing city [37-39].

Table 1. Crop management data obtained from three field experiments conducted in Heilongiiang Province, China, and used in the AquaCrop model calibration and verification.

\begin{tabular}{|c|c|c|c|c|}
\hline & \multicolumn{2}{|c|}{ 1st Experiment } & 2nd Experiment & 3rd Experiment \\
\hline Location & \multicolumn{2}{|c|}{$\left(126^{\circ} 36^{\prime} 35^{\prime \prime} \mathrm{E}, 45^{\circ} 43^{\prime} 09^{\prime \prime} \mathrm{N}\right)$} & $\begin{array}{l}\left(125^{\circ} 35^{\prime} 10^{\prime \prime} \mathrm{E},\right. \\
\left.45^{\circ} 17^{\prime} 31^{\prime \prime} \mathrm{N}\right)\end{array}$ & $\begin{array}{l}\left(125^{\circ} 17^{\prime} 57^{\prime \prime} \mathrm{E},\right. \\
\left.45^{\circ} 42^{\prime} 57^{\prime \prime} \mathrm{N}\right)\end{array}$ \\
\hline Year & $\begin{array}{l}29 \text { April-27 September } \\
2014\end{array}$ & $\begin{array}{l}28 \text { April-24 September } \\
2015\end{array}$ & $\begin{array}{l}28 \text { April-27 September } \\
2014\end{array}$ & $\begin{array}{l}\text { 3 May-27 September } \\
2017\end{array}$ \\
\hline Treatment & Irrigation $^{1}$ & Irrigation $^{1}$ & Irrigation $^{2}$ & Rainfed $^{3}$ \\
\hline Irrigation period & $\begin{array}{l}\text { Seedling stage } \\
\text { Jointing stage } \\
\text { Tasseling stage } \\
\text { Milk ripening stage }\end{array}$ & $\begin{array}{l}\text { Seedling stage } \\
\text { Jointing stage } \\
\text { Tasseling stage } \\
\text { Milk ripening stage }\end{array}$ & $\begin{array}{l}\text { Tasseling stage } \\
\text { Milk ripening stage } \\
\text { Jointing stage }\end{array}$ & None \\
\hline Irrigation limitation (\%) & $80 \mathrm{FC}^{4}$ & $80 \mathrm{FC}$ & none & 0 \\
\hline Irrigation ceiling (\%) & $100 \mathrm{FC}$ & $100 \mathrm{FC}$ & none & 0 \\
\hline
\end{tabular}


Table 1. Cont.

\begin{tabular}{|c|c|c|c|c|}
\hline & \multicolumn{2}{|c|}{ 1st Experiment } & 2nd Experiment & 3rd Experiment \\
\hline Irrigation quota (mm) & $300 \sim 400$ & $300 \sim 400$ & 400 & 0 \\
\hline Data used in AquaCrop & Calibration & Verification & Verification & Verification \\
\hline
\end{tabular}

\subsection{AquaCrop Model Principle}

\subsubsection{AquaCrop Model Description}

The weather model included precipitation, reference crop evapotranspiration $\left(E T_{0}\right)$, $\mathrm{CO}_{2}$, and maximum air temperature, minimum air temperature, and daily $E T_{0}$ was calculated by the Penman-Monteith equation recommended by the FAO [40,41]. The crop model included crop growth, development, senescence, and yield. The management submodels included irrigation and field management practices; the soil models included soil and water balance management. The four main production processes were simulated using a daily time step and included crop development, transpiration $\left(T_{r}\right)$, aboveground biomass production, and yield.

First, we used the green canopy cover (CC) in AquaCrop to simulate crop growth, development, and aging. $C C$ was then used in conjunction with $E T_{0}$ and the transpiration coefficient $\left(K_{c T r}\right)$ to calculate transpiration. Similarly, soil evaporation was calculated using the soil evaporation coefficient, $C C$, and $E T_{0}$ [31].

\subsubsection{From the $K_{y}$ Approach to the AquaCrop Model}

The yield response to water $\left(K_{y}\right)$ is used here to describe the relationship between crop yield and water stress due to the insufficient water supply by precipitation or irrigation during the growing period. In FAO.33, an empirical production function is used to assess the yield response to water [42]:

$$
\left(1-\frac{Y}{Y_{x}}\right)=K_{y}\left(1-\frac{E T}{E T_{x}}\right)
$$

where $Y_{\mathrm{x}}$ (ton/ha) and $Y$ (ton/ha) are the maximum and actual yield, and $\left(1-Y / Y_{\mathrm{x}}\right)$ is the relative yield decline. $E T_{X}(\mathrm{~mm})$ and $E T(\mathrm{~mm})$ are the maximum and actual evapotranspiration, $\left(1-E T / E T_{x}\right)$ is the relative water stress, and $K_{y}$ is the proportionality factor between the relative yield decline and relative reduction in $E T$. When $K_{y}>1$ : crop response is very sensitive to water deficit with proportional larger yield reductions when water use is reduced because of stress. When $K_{y}<1$ : crop is more tolerant to water deficit and recovers partially from stress, exhibiting less than proportional reductions in yield with reduced water use. When $K_{y}=1$ : yield reduction is directly proportional to reduced water use.

\subsubsection{Evapotranspiration and Yield}

This model estimates transpiration and yield by establishing canopy growth and senescence models. For our study, $E T_{c}$ was divided into transpiration and evaporation components to avoid the impact of the unproductive consumption (evaporation) of water [43-45]. Under the rainfed scenario, crops may be subjected to water stress, in which case, the crop evapotranspiration is $E T_{a}$. The Formulas (2) and (3) in AquaCrop for calculating crop transpiration $\left(T_{\mathrm{r}}, \mathrm{mm} /\right.$ day), soil evaporation $(E, \mathrm{~mm} /$ day), and final grain yield $(Y$, ton $/$ ha) are as follows [46]:

$$
\begin{gathered}
T_{r}=K_{s} K_{S_{\operatorname{Tr}}}\left(K_{\mathcal{C}_{T_{r, x}}} C C^{*}\right) E T_{0} \\
E=K_{r}\left(1-C C^{*}\right) K_{e x} E T_{0}
\end{gathered}
$$




$$
Y=f_{H I} H I_{0} B
$$

where $C C^{*}$ is the actual canopy cover (\%) adjusted for micro-advective effects, $K_{s}$ is the crop coefficient, and $K_{s T r}$ is temperature stress. $K_{c T r}, x$ is the maximum standard crop transpiration coefficient (dimensionless), $E T_{0}$ is the grass-reference evapotranspiration (mm/day), $K_{r}$ is the evaporation reduction coefficient used to adjust for the effect of insufficient water in the topsoil layer, $K_{e x}$ is the maximum soil evaporation coefficient, $f_{H I}$ is the adjustment factor for water stresses, $H I_{0}$ is the reference harvest index, and $B$ is the aboveground dry biomass (ton/ha).

\subsection{Scenario Setting and Maize Irrigation Water Requirements}

In this study, we developed two scenarios to explore the changes in irrigation water supply and the requirements and yield of maize in Heilongjiang Province:

1. Rainfed: The distribution of precipitation in Heilongjiang Province was uneven over the four seasons. Past studies showed that the distribution of precipitation in Heilongjiang Province has decreased in recent decades and that most of the maize planting in this region relies on rainfed farming [35]. The rainfed scenario involves the use of precipitation alone, without irrigation.

2. Irrigation: In this study, irrigation without a water shortage was used to compare the differences in maize $E T_{a}, E T_{c}, I_{r}$, yield, and WUE between the rainfed and irrigated scenarios. In the AquaCrop model, irrigation management was achieved through irrigation timing and the number of irrigation events during the crop growing season. In the irrigation scenario, maize was considered fully irrigated when the soil water content reached $80 \%$ field capacity, with $100 \%$ field capacity achieved by the end of the day to restore root zone moisture.

\subsection{AquaCrop Model Data and Evaluation}

The AquaCrop model provides default parameters for maize, but these default parameters cannot sufficiently reflect $E T_{a}, E T_{c}$, and yield during maize growing stages when used; the default parameters need to be verified (Table 2). The calibration procedure followed the guidelines outlined in the AquaCrop Reference Manual and FAO Irrigation and Drainage Document No.66, Crop Yield Responses to Water [46]. The experiments used for calibration and verification are shown in Table 1.

Table 2. Default and calibrated maize parameters for Aquacrop used in this study.

\begin{tabular}{ccc}
\hline Parameter & Default & Calibrated \\
\hline Conservative & & \\
Base temperature $\left({ }^{\circ} \mathrm{C}\right)$ & 5.5 & 5.5 \\
Cut off temperature $\left({ }^{\circ} \mathrm{C}\right)$ & 30 & 30 \\
Crop transpiration $\left(\mathrm{cm}^{2}\right.$ plr $)$ & 6.5 & 6.5 \\
Canopy $\left.{ }^{-1}\right)$ & 1.10 & 1.10 \\
Cover per seedling $\left(P_{\text {upper }}\right)$ & 0.25 & 0.25 \\
Canopy expansion stress coefficient & 0.6 & 0.6 \\
Crop water productivity $\left(W P^{*}\right)$ & 17 & 32 \\
Initial canopy cover $\left(C C_{0}\right)$ & 1.2 & 0.36 \\
Maximum canopy cover $(\%)$ & 80 & 90 \\
Reference harvest index & 50 & 40 \\
Non-conservative & & 15 \\
Time from sowing to emergence $($ day) & 5 & 80 \\
Time from sowing to max canopy cover $($ day) & 70 & 99 \\
Time from sowing to flowering (day) & 87 & 134 \\
Time from sowing to senescence $($ day) & 120 & 1.0 \\
Maximum effective rooting depth $(\mathrm{cm})$ & 1.0 & 56,000 \\
Plant density (plants ha ${ }^{-1}$ ) & 185,000 & \\
\hline
\end{tabular}


The output of the AquaCrop model compared to the field measurements was assessed using both qualitative and quantitative approaches. The qualitative approach involved the use of graphical interpretations of the results to evaluate the trends in simulated and measured data. The quantitative approach consisted of using statistical indicators such as the root mean square error (RMSE), the normalized root mean square error (NRMSE), the Nash-Sutcliffe model efficiency coefficient $(E F)$, the coefficient of determination $\left(R^{2}\right)$, and Willmott's index of agreement $(d)$.

The RMSE measures the magnitude of difference between simulated and observed values and ranges from 0 to positive infinity, with 0 indicating good model performance and positive infinity indicating poor model performance [47]:

$$
\begin{gathered}
R M S E=\sqrt{\frac{\sum_{i=1}^{n}\left(S_{i}-M_{i}\right)^{2}}{n}} \\
\text { NRMSE }=\frac{100 R M S E}{\bar{O}}
\end{gathered}
$$

where $M_{i}$ and $S_{i}(i=1,2, \ldots, \mathrm{n})$ represent the measured and simulated values, and $\bar{O}$ is the average of the measured values. If $N R M S E<10 \%$, the verification is considered to have a high degree of fit. If the NRMSE is between $10 \%$ and $20 \%$, the fit is deemed good. If the NRMSE is between 20 and $30 \%$, the verification is considered acceptable in terms of goodness-of-fit. If the value is greater than $30 \%$, the verification fit is assumed to be poor [48].

The $E F$ (ranging from 1 to negative infinity) determines the relative size of the residual value and the degree of fit between the observed data and the simulated data. An $E F$ close to 1 indicates that the residual value is small and that the model offers a reasonable simulation. $R^{2}$ is the coefficient of determination (goodness-of-fit). The better the goodnessof-fit, the higher the independent variable's explanation for the dependent variable [49]. Here, $d$ ranges from 0 to 1 , indicating that the model performance is better when $d$ is close to 1 . The calculation formula is as follows:

$$
\begin{gathered}
E F=1-\frac{\sum_{i=1}^{n}\left(S_{i}-M_{i}\right)^{2}}{\sum_{i=1}^{n}\left(M_{i}-\bar{M}\right)^{2}} \\
d=1-\frac{\sum_{i=1}^{n}\left(S_{i}-O_{i}\right)^{2}}{\sum_{i=1}^{n}\left(\left|S_{i}-O_{i}\right|+\left|O_{i}-\bar{O}\right|\right)^{2}}
\end{gathered}
$$

where $\bar{M}$ represents the mean value, and $R^{2}$ and $E F$ are used to quantify the predictive ability of the model, while the RMSE represents the model prediction error.

\subsection{Division of Hydrological Years}

The precipitation during the maize growing season at different sites levels from 1960 to 2015 was arranged in decreasing order of magnitude. Formula (9) was used to calculate the empirical frequency and draw the logarithmic normal distribution map to obtain the precipitation, precipitation values at $F_{a}=95 \%, 75 \%, 50 \%, 25 \%$ probability were defined as extremely dry year, dry year, normal year, and wet year [50] The average precipitation during the maize growing season in extremely dry, dry, normal, and wet year were 256.1, 333.6, 410.4, $487.9 \mathrm{~mm}$ in Heilongjiang Province. The precipitation varies in different regions, but we strictly follow the formula:

$$
F a=\frac{100 m}{n+1}
$$

where $F_{a}$ is the empirical frequency of $m$ items in the observation series, $m$ is the sequence number of the observation series arranged from large to small, and $n$ is the number of years in the observation series. 


\subsection{Water Use Efficiency}

Increasing crop WUE is the key to increasing agricultural productivity under limited water resources. WUE refers to the amount of assimilated matter produced per unit of water consumed during crop production, reflecting the relationship between the yield and ET of crops [37]. The calculation method is as follows:

$$
W U E=\frac{Y}{E T}
$$

where WUE is expressed in $\mathrm{kg} / \mathrm{m}^{3}$ based on units of water volume, $E T$ is evapotranspiration $(\mathrm{mm})$, and $Y$ is grain yield (ton/ha).

\subsection{Data Processing}

In this paper, we used the spatial analysis function of ArcMap 10.5 toolbox to interpolate the spatial distribution maps of $E T_{c}, E T_{a}, I_{r}$, yield, and WUE in different hydrological years.

\section{Results}

\subsection{Calibration and Verification of the AquaCrop Model}

\subsubsection{Crop Water Requirement}

Figure 2 illustrates a comparison between the measured and simulated values of $E T_{c}$ at all growth stages, based on a calibration of AquaCrop in Harbin 2014. The corrected model underestimated the $E T_{c}$ with values $15 \sim 30 \mathrm{~mm}$ in the late growth period (Figure 2). However, the model showed a high degree of fit overall, with low RMSE $(19.56 \mathrm{~mm})$ and NRMSE (14.25\%) and acceptable EF (0.87) and $d(0.67)$ values.

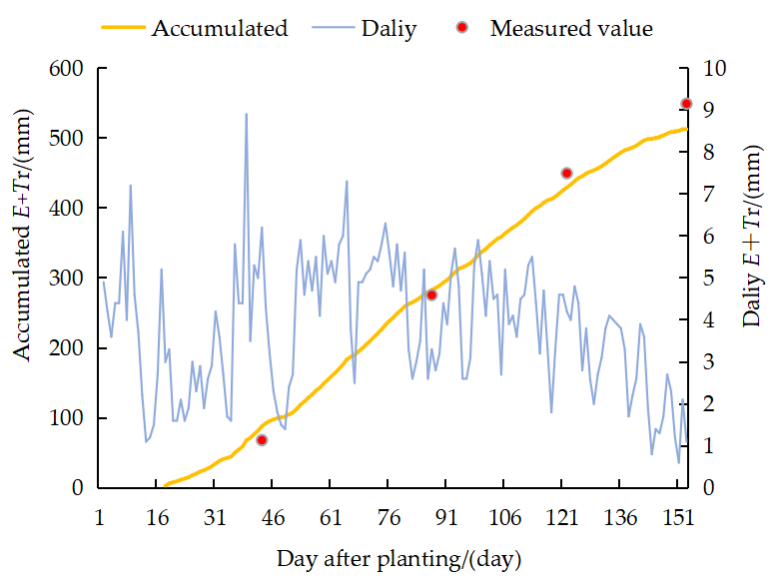

Figure 2. Simulated and measured accumulated $E T_{c}\left(E+T_{r}\right)$ during the growing season in Harbin, 2014. ET: soil evaporation, $T_{r}$ : crop transpiration, same as below.

The measured and simulated values of $E T_{c}$ at different growth stages were compared and verified by the data for Harbin in 2015 and Zhaozhou in 2014 and 2017 (Figure 3). In the verification process, AquaCrop was used to simulate the growth trend of maize during the growth seasons. However, as the model underestimated the $E T_{\mathcal{c}}$ with the value of $10 \sim 30 \mathrm{~mm}$ in the later growth stage, the degree of underestimation was less than that of the calibration 50 60 mm. Figure 4 illustrates a comparison between all the measured and simulated values listed in Table 3; these values provided the goodness-of-fit parameters for model calibration and verification in all years and locations. AquaCrop underestimated the $E T_{c}$ during calibration, and the results showed an overestimation of $E T_{c}$ though $R^{2}$ close to 1 , during verification, especially for the verified $E T_{a}\left(R^{2}=0.68\right)$ in Figure 4. In general, the model provided a high degree of fit between the simulated and measured values. 


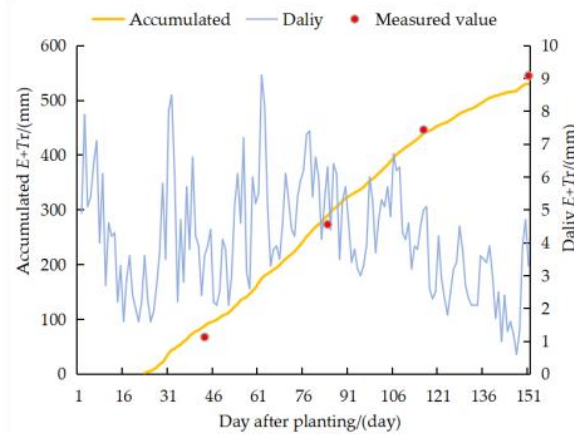

(a) Harbin, 2015

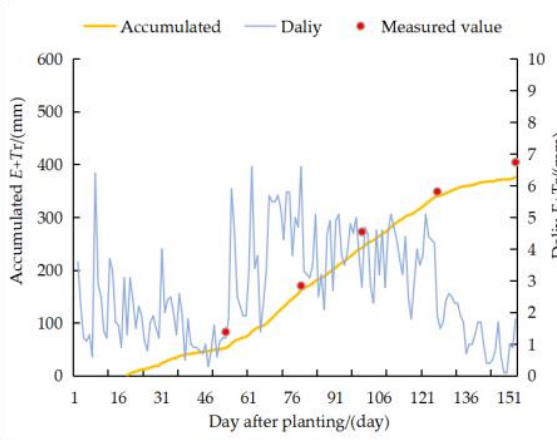

(b) Zhaozhou, 2014

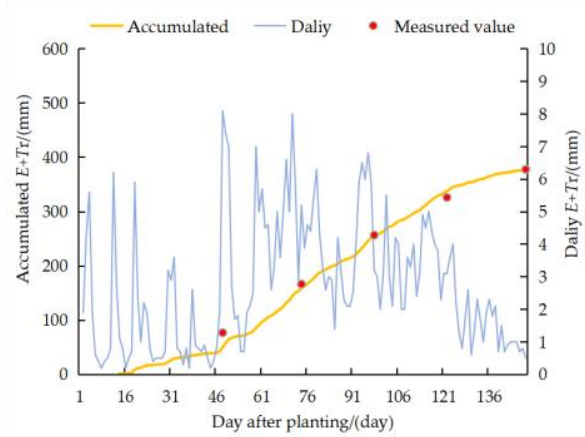

(c) Zhaozhou, 2017

Figure 3. Simulated and measured accumulated $E T_{c}\left(E+T_{r}\right)$ and $E T_{a}\left(E+T_{r}\right)$ from model verification during the growing seasons in (a) Harbin (2015), (b) Zhaozhou (2014), and (c) Zhaozhou (2017).

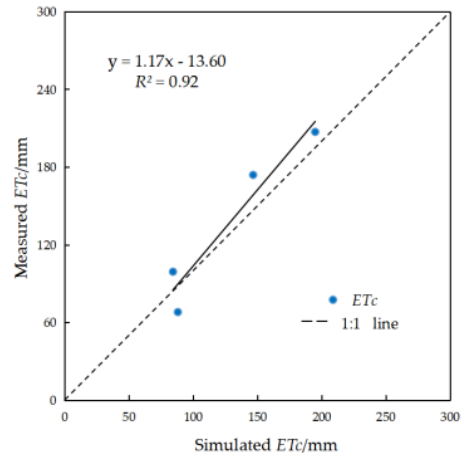

(a)

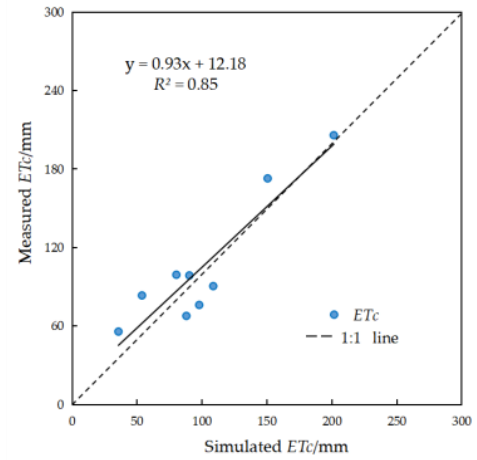

(b)

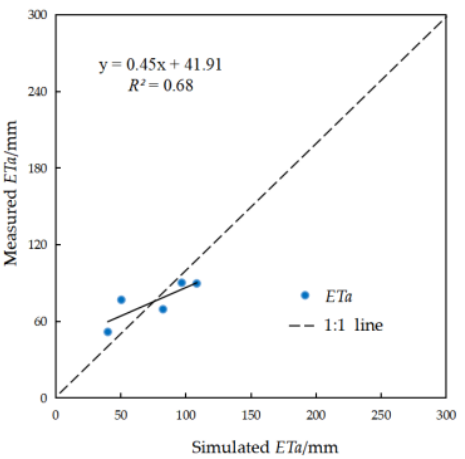

(c)

Figure 4. Calibration for (a) Harbin (2014) and verification of the measured and simulated $E T_{c}$ for (b) Harbin (2015) and Zhaozhou (2014); (c) $E T_{a}$ for Zhaozhou (2017) under the irrigation and rainfed scenarios. $E T_{c}$ : crop water requirements, $E T_{a}$ : actual crop evapotranspiration, same as below.

Table 3. The goodness-of-fit indexes from the growing-season model simulation: yields in 2014, 2015, and 2017.

\begin{tabular}{lccccc}
\hline \multirow{2}{*}{ Location (Year) } & \multicolumn{4}{c}{ The Goodness-of-Fit Parameters } \\
& & RMSE (mm) & NRMSE (\%) & EF & $\boldsymbol{d}$ \\
\hline \multirow{2}{*}{ Calibration } & Harbin (2014) & 19.56 & 14.25 & 0.87 & 0.67 \\
\hline \multirow{3}{*}{ Verification } & Harbin (2015) & 15.79 & 11.59 & 0.92 & 0.94 \\
& Zhaozhou (2014) & 19.85 & 24.51 & -0.66 & 0.66 \\
& Zhaozhou (2017) & 16.70 & 22.08 & 0.60 & 0.64 \\
\hline
\end{tabular}

\subsubsection{Yield}

The yields of four experiments were used for calibration and verification. The measured and simulated yields are shown in Figure 5. The model results indicate that the simulated yield overestimated the actual yield less than 0.6 ton/ha with $R^{2}(0.9)$ close to 1. The model had low RMSE (0.595 ton/ha) and NRMSE (4.2\%) values and acceptable EF (0.98), $d(0.9)$, and $R^{2}(0.901)$ values. 


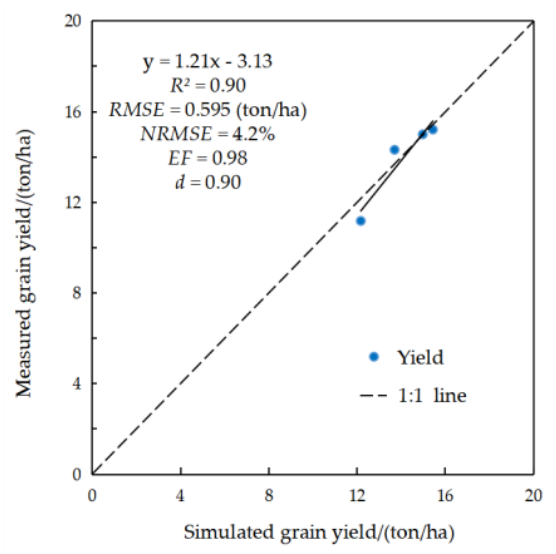

Figure 5. Calibration and verification results for the measured and simulated yields in all years (Zhaozhou (2014), Harbin (2014-2015), and Zhaozhou (2017).

\subsection{Comparison of $E T_{c}$ and $E T_{a}$ in Different Hydrological Years}

The characteristics of $E T_{a}$ and $E T_{c}$ in the growing season of maize were then determined. The spatial distribution patterns of $E T_{a}$ and $E T_{c}$ were generally similar over the four hydrological years-first decreasing and then increasing from west to east. High $E T_{c}$ and $E T_{a}$ with values greater than 500 and $400 \mathrm{~mm}$ were located along the strip extending from the west to the south (Figure 6). As a whole, the average $E T_{c}$ decreased from the extremely dry years to wet years, with values of $499,464,453$, and $423 \mathrm{~mm}$, respectively. The value of the average $E T_{a}$ increased from the extremely dry years to normal years and varied weakly from normal years to wet years. The average $E T_{a}$ values were $144,82,52$, and $31 \mathrm{~mm}$ lower, respectively, than the average $E T_{\mathcal{c}}$ values.

Rainfed

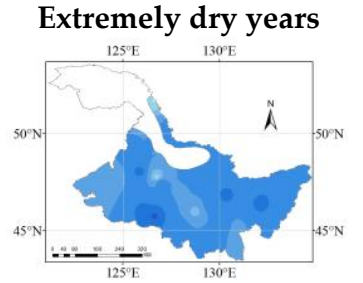

(a)

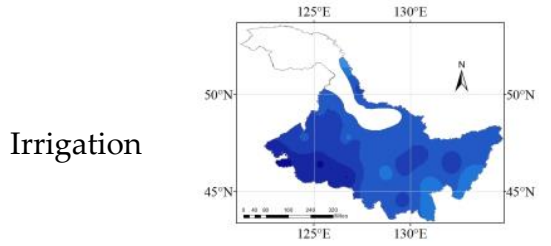

(e)

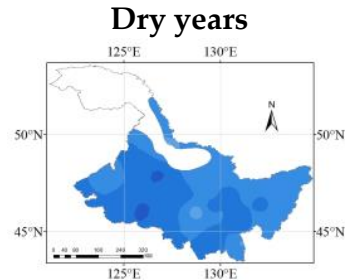

(b)

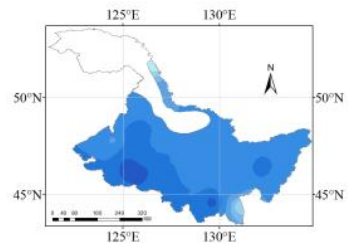

(f)

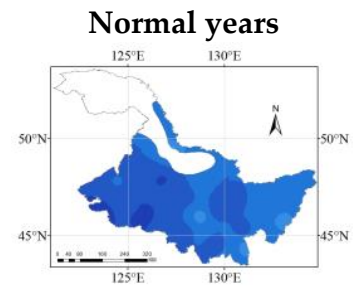

(c)

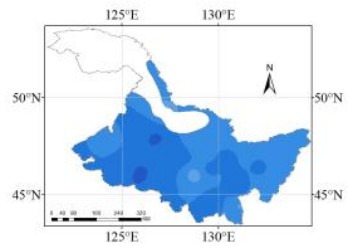

(g)

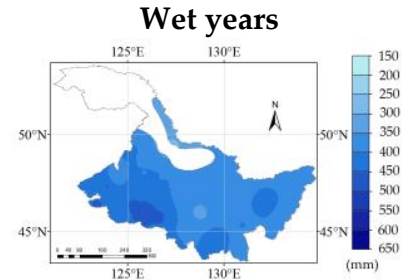

(d)

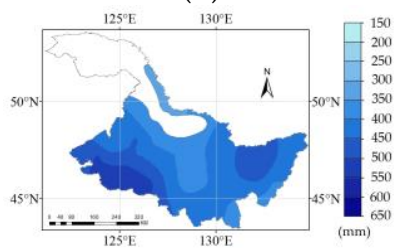

(h)

Figure 6. Spatial distribution of $E T_{a}$ and $E T_{c}$ in extremely dry years $(\mathbf{a}, \mathbf{e})$, dry years $(\mathbf{b}, \mathbf{f})$, normal years $(\mathbf{c}, \mathbf{g})$, and wet years $(\mathbf{d}, \mathbf{h})$ under rainfed and irrigation scenarios.

\subsection{Spatial Distribution of $I_{r}$ in Different Hydrological Years}

Weak variations in $I_{r}$ trends were observed between the four hydrologic years in the different regions, with a decreasing trend from west to east over the four hydrological years (Figure 7). The average $I_{r}$ values were 289, 212, 141, and $80 \mathrm{~mm}$, and high values were mainly distributed in the west, similar to the locations of $E T_{c}$, greater than 400, 300, 200, $100 \mathrm{~mm}$ in the extremely dry years, dry years, normal years, and wet years, respectively. 


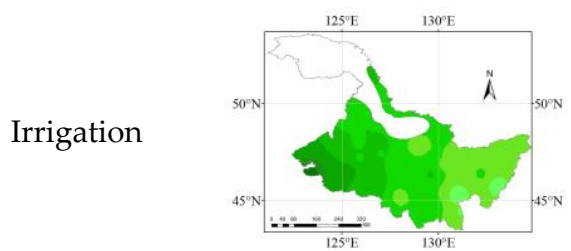

(a)

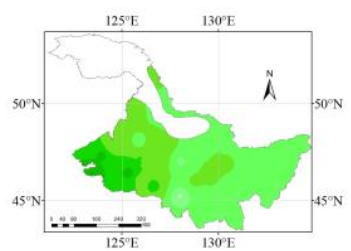

(b)

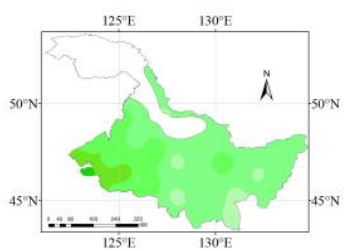

(c)

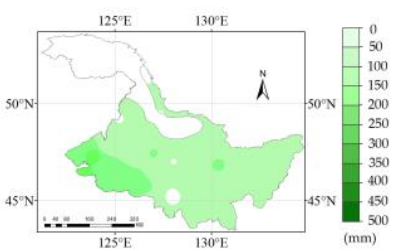

(d)

Figure 7. Spatial distribution of $I_{r}$ in extremely dry years (a), dry years (b), normal years (c), and wet years (d) under irrigation scenario.

\subsection{Spatial Distribution of Yield in Different Hydrological Years under Rainfed and Irrigation Scenarios}

The average yields under the rainfed scenario during the extremely dry years, dry years, normal years, and wet years were 9.59, 11.32, 11.73, and 11.71 ton/ha, respectively. Irrigation increased maize yield in most areas during the extremely dry and dry years by 2.18 and 0.55 ton/ha, respectively, especially in the regions where $E T_{\mathcal{C}}$ and $I_{r}$ were high. However, in the normal and wet years, irrigation only increased the yield by 0.03 and 0.05 ton/ha, respectively (Figure 8). The high yield values greater than 13.0 ton/ha were mainly distributed in the southwest, while the low yield values less than 8.5 ton/ha were primarily distributed in the eastern regions.

Extremely dry years

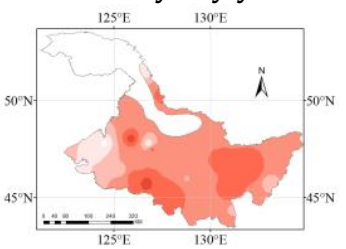

(a)

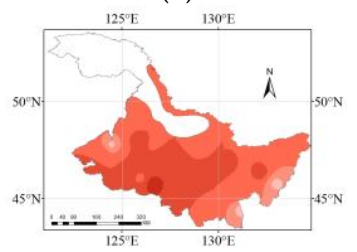

(e)

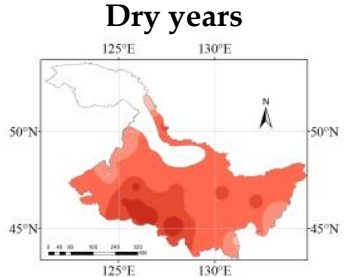

(b)

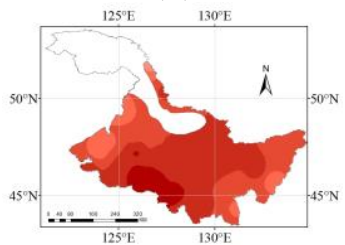

(f)

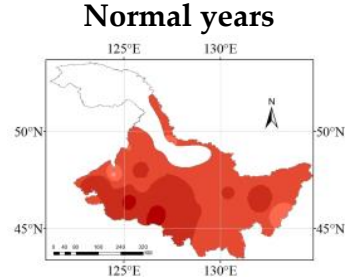

(c)

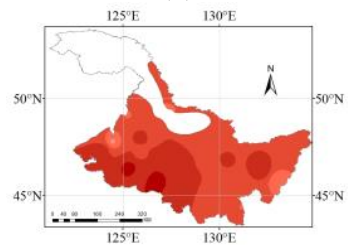

$(\mathrm{g})$

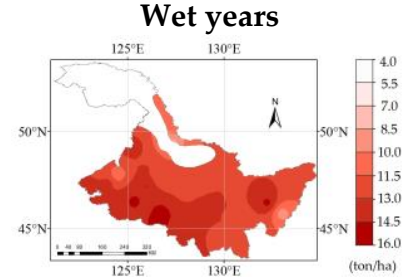

(d)

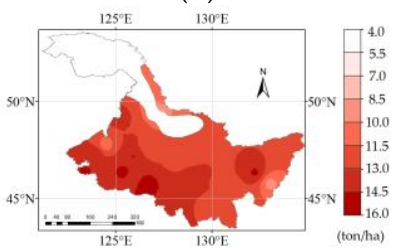

(h)

Figure 8. Spatial distribution of yield in extremely dry years $(\mathbf{a}, \mathbf{e})$, dry years $(\mathbf{b}, \mathbf{f})$, normal years $(\mathbf{c}, \mathbf{g})$, and wet years $(\mathbf{d}, \mathbf{h})$ under the rainfed and irrigation scenario.

\subsection{Spatial Distribution of WUE in Different Hydrological Years under Rainfed and Irrigation} Scenarios

WUE showed a trend of increasing first and then decreasing from the western to the eastern regions over the four hydrological years (Figure 9). The average WUE under the rainfed scenario in the respective extremely dry years, dry years, normal years, and wet years was $2.70,3.00,2.95$, and $2.99 \mathrm{~kg} / \mathrm{m}^{3}$. The average WUE under the irrigation scenario was $0.32,0.4,0.33$, and $0.21 \mathrm{~kg} / \mathrm{m}^{3}$ lower than that under the rainfed scenario in the extremely dry years, dry years, normal years, and wet years. Overall, irrigation reduced the WUE over the four hydrological years, especially during normal and wet years. Irrigation did not significantly improve the WUE and yield in most areas; thus, rainfed farming could be employed as an alternative schedule. 


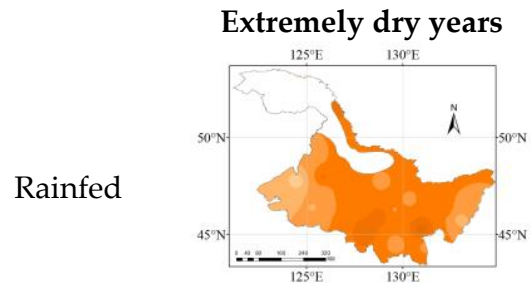

(a)

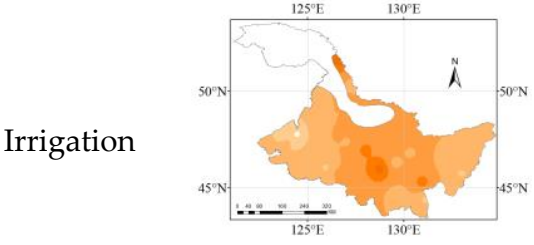

(e)

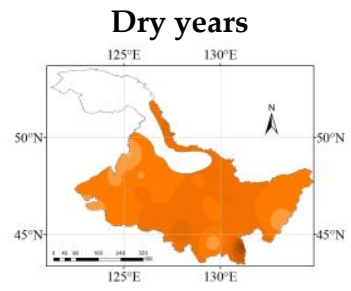

(b)

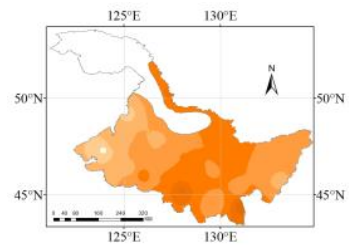

(f)

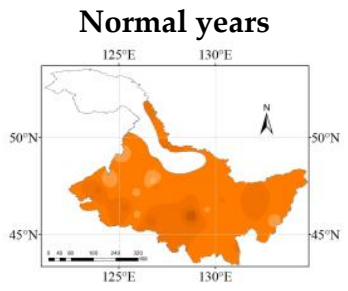

(c)

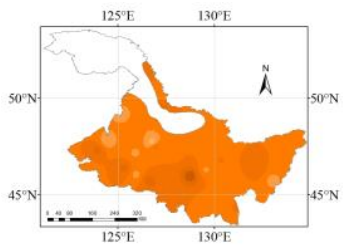

(g)

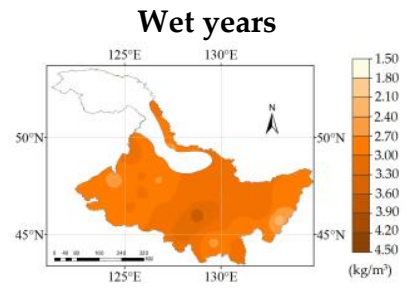

(d)

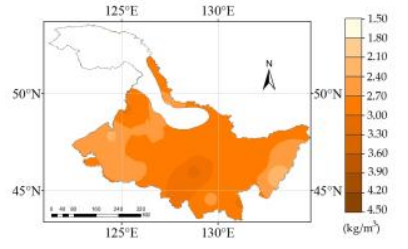

(h)

Figure 9. Spatial distribution of WUE in extremely dry years $(\mathbf{a}, \mathbf{e})$, dry years $(\mathbf{b}, \mathbf{f})$, normal years $(\mathbf{c}, \mathbf{g})$, and wet years $(\mathbf{d}, \mathbf{h})$ under the rainfed and irrigation scenarios.

\section{Discussion}

The results demonstrated that AquaCrop performed well in simulating $E T_{\mathcal{c}}$ and maize yield (Figures 4 and 5), with acceptable RMSE, NRMSE, EF, and $d$ values (Table 3). However, AquaCrop underestimated $E T_{c}$ in the final simulation (Figures 3 and 4). Ultimately, the result for $E T_{\mathcal{C}}$ was lower than the actual result. Rupinder indicated that under irrigation and rainfed scenarios, the AquaCrop model consistently underestimates the trends of $E T_{\mathcal{c}}$ [31]. Thus, the observed bias in simulated values was most likely due to insufficient parameterization of the crop parameters during later growth stages, as the model was highly impacted by crop senescence stress coefficients [27,51]. In this study, due to the limited data, adjustments in the canopy decline may have affected the correction of $E T_{\mathcal{C}}$ for the later growth stages.

Many previous studies indicated that high values of $E T_{c}$ are mainly distributed in the western regions [52,53], with an average of $401.64 \mathrm{~mm}$, while low values are primarily distributed in the eastern regions [34]. In [34], the spatial distribution of $E T_{c}$ was the same as that in this study, but the value of $E T_{\mathcal{c}}$ was greater than $401.64 \mathrm{~mm}$, which may have been caused by the use of different models and methods. The previous study used a single crop coefficient to calculate $E T_{c}$. However, the present study used the AquaCrop model with two crop coefficients ( $E$ and $T_{r}$ ) and considered the impact of $C O_{2}$ on $E T_{c}$ [45]. Studies have shown that the use of two crop coefficients offers more accuracy than the use of a single crop coefficient and that predicting $E T_{\mathcal{C}}$ using two crop coefficients provides better performance than predicting $E T_{\mathcal{C}}$ using a single crop coefficient [54]. In the present study, the AquaCrop model was calibrated and verified using experimental data from the field. The results obtained through this method may be more reliable than those acquired by calibrating $K_{c}$ in the CropWAT model using the FAO-56 method. Furthermore, a more reliable localized AquaCrop model will require more experimental data for calibration and verification. In future studies, we will further optimize the AquaCrop model to make it more accurate and applicable to more crop simulations.

The present study demonstrated that, in the west, $I_{r}$ was high while the yield and $W U E$ were low. Nie indicated that $E T_{c}$ and $I_{r}$ in each accumulated temperature zone are increased with increasing temperature, confirming the spatial distribution trend of $E T_{\mathcal{c}}$ and $I_{r}$ in this study [51]. Sun showed that precipitation in the maize growing season fluctuates strongly in the west [55], which may be one reason for the large amount of irrigation in these regions. Moreover, due to the high accumulated temperature, relatively low air humidity, strong solar radiation, and high maize $E T_{\mathcal{c}}$, drought frequently occurred in the west [56]. Past research has shown that the increase in greenhouse gases in Heilongjiang Province has affected radiation to a certain extent, thereby increasing $E T_{0}$. However, the 
$E T_{0}$ in the northeast slightly decreased. This trend reduced the $E T_{c}$ and the potential $I_{r}$ for ET [57]. Moreover, research has shown that the water shortage in the west improved from 1960 to 2015 [34]. Based on this trend, the $E T_{0}$ will alleviate drought in the west, which will be beneficial for employing a rainfed schedule during normal and wet years in Heilongiiang Province.

Under the studied irrigation scenarios, the WUE was lower than that under the rainfed scenario. In extremely dry and dry years, irrigation alleviated drought and increased maize yields in most regions. Moreover, the water supply increased as the ET increased, and the WUE was low, possibly because the additional water supply contributed to biomass production rather than an increase in the yield [58]. During normal and wet years, irrigation did not significantly increase the yield. The results further demonstrate that excess irrigation may be lost through deep percolation. Therefore, except for the WUE being lower under the irrigation scenario, there was no significant difference in the spatial distribution between the two hydrological years. In the future, based on the water-saving principle, irrigation should not be considered during normal and wet years. When irrigation is necessary during extremely dry years and dry years, a water-saving irrigation schedule (such as drip irrigation under mulch or the use of sprinklers) needs to be implemented under appropriate agricultural management strategies to improve WUE. These measures are essential to increase the yields of similar crops under the same climate regions and provide a basis for optimizing the allocation of water resources and improving the WUE of maize planted in Heilongjiang Province.

\section{Conclusions}

In this study, the data from three field experiments on maize were used to calibrate and validate the AquaCrop model in Heilongjiang Province. The $E T_{c}, E T_{a}, I_{r}$, and yield were correctly simulated under rainfed and irrigation scenarios over four hydrological years. The results demonstrated that in the west, the $E T_{\mathcal{c}}, E T_{a}$, and $I_{r}$ were high, but the yield was low. Moreover, irrigation increased the yield in extremely dry years, while there were no significant changes during normal and wet years. The WUE under irrigation was lower than that under the rainfed scenario. Notably, in normal and wet years, irrigation did not increase yield but instead reduced WUE. Therefore, the planting area may not require irrigation during normal and wet years, but the drought in the western area of Heilongjiang Province cannot be ignored.

The results obtained by the localized AquaCrop model may provide a reference for areas with similar phenology in Heilongjiang Province. Due to limited experimental data used for calibration and verification in this study, the AquaCrop model still has a deviation. In the future, we will focus on calibrating the AquaCrop model with more field experiments, dividing rainfed and irrigation districts, and formulating irrigation schedules for irrigation districts to guide agricultural irrigation in Heilongjiang Province.

Author Contributions: T.N. collected the data; Y.J. and T.N analyzed data; Y.J. wrote the paper; Y.T., N.L., T.W. and C.D. drew the figures for this paper; Z.Z., T.L., S.Z., Z.S. and F.L. reviewed and edited the paper. All authors have read and agreed to the published version of the manuscript.

Funding: This work was fund by the Basic Scientific Research Fund of Heilongiiang Provincial Universities, grant number RCCXYJ201912\&2018-KYYWF-1570, National Natural Science Foundation Project of China, grant number 51809042.

Institutional Review Board Statement: Not applicable.

Informed Consent Statement: Not applicable.

Acknowledgments: We thank the Chinese meteorological data sharing service (http:/ /data.cma.cn, accessed on 22 July 2021) for providing the meteorological data. We thank the anonymous reviewers and the editor for their suggestions, which substantially improved the manuscript.

Conflicts of Interest: The authors declare no conflict of interest. 


\section{References}

1. UNEP. Global Environmental Outlook. 2000. Available online: http://www.unep.org/geo/geo2000/english/index.htm (accessed on 7 July 2021).

2. Rijsberman, F.R. Water scarcity: Fact or fiction? Agric. Water Manag. 2006, 80, 5-22. [CrossRef]

3. Crow, B. Contesting water injustice: The Santa Cruz Declaration on the global water crisis. Water Int. 2014, 39, 246-261. [CrossRef]

4. Tittonell, P.; Giller, K.E. When yield gaps are poverty traps: The paradigm of ecological intensification in African smallholder agriculture. Field Crops Res. 2013, 143, 76-90. [CrossRef]

5. FAO. FAO Statistical Yearbook 2007: World Food and Agriculture. Available online: http://www.fao.org/docrep/018/i3107e/i3 107e00.htm (accessed on 7 July 2021).

6. Beshir, S. Review on Estimation of Crop Water Requirement, Irrigation Frequency and Water Use Efficiency of Cabbage Production. J. Geosci. Environ. Prot. 2017, 5, 59-69. [CrossRef]

7. Sandhu, R.; Irmak, S. Performance of AquaCrop model in simulating maize growth, yield, and evapotranspiration under rainfed, limited and full irrigation. Agric. Water Manag. 2019, 223, 105687. [CrossRef]

8. Kehlenbeck, K.; Jamnadass, R. Food and Nutrition-Fruits, Nuts, Vegetables and Staples from Trees. In Treesilience: An Assessment of the Resilience Provided by Trees in the Drylands of Eastern Africa; De, L.J., Njenga, M., Wagner, B.I., Eds.; ICRAF: Nairobi, Kenya, 2014; Chapter 6.2.1; p. 166. ISBN 978-92-9059-352-2.

9. Alexandratos, N.; Bruinsma, J. World Agriculture towards 2030/2050: The 2012 Revision; ESA Working Paper No. 12-03; FAO of UN: Rome, Italy, 2012; Chapter 2.1.2; pp. 32-33.

10. Zhang, Q.S.; Shi, Q.L.; Chen, C.; Shi, Q. Impacts of land use and land cover changes on surface energy and water balance in the Heihe River Basin of China, 2000-2010. Phys. Chem. Earth 2015, 79-82, 2-10. [CrossRef]

11. Qian, X.; Wei, S.A.; Ying, Z.C. Forecast and optimal allocation of production, living and ecology water consumption in Zhangye, China. Phys. Chem. Earth 2016, 96, 16-25. [CrossRef]

12. Deng, X.P.; Lun, S.; Zhang, H.; Turner, N.C. Improving agricultural water use efficiency in arid and semiarid areas of China. Agric. Water Manag. 2006, 80, 23-40. [CrossRef]

13. Yang, X.L.; Chen, Y.Q.; Pacenka, S.; Steenhuis, T.S.; Sui, P. Managing food and bioenergy crops with declining groundwater levels in the North China Plain. Field Crops Res. 2019, 234, 1-14. [CrossRef]

14. Ammar, M.E.; Davies, E. On the accuracy of crop production and water requirement calculations: Process-based crop modelling at daily, semi-weekly, and weekly time steps for integrated assessments. J. Environ. Manag. 2019, 238, 460-472. [CrossRef]

15. Adeboye, O.; Schultz, B.; Adekalu, K.O.; Prasad, K. Performance evaluation of AquaCrop in simulating soil water storage, yield, and water productivity of rainfed soybeans (Glycine max L. merr) in Ile-Ife, Nigeria. Agric. Water Manag. 2019, 213, 1130-1146. [CrossRef]

16. Nie, T.Z.; Liang, Q.Z.; Wang, T.Y.; Chu, L.L.; Chen, X.; Li, F.R. Water requirement and supply and irrigation schedule formulation for maize in the western region of Heilongjiang Province. South-to-North Water Transfers and Water Sci. Technol. $2021,1-13$. Available online: http:/ / kns.cnki.net/kcms / detail/13.1430.TV.20210628.1130.002.html (accessed on 7 July 2021).

17. Allen, R.G.; Walter, I.A.; Elliott, R.L. The ASCE Standardized Reference Evapotranspiration Equation; ASCE: Reston, VA, USA, 2005; pp. 46-47. [CrossRef]

18. Sun, H.Y.; Shen, Y.J.; Yu, Q.; Flerchinger, G.N. Effect of precipitation change on water balance and WUE of the winter wheatsummer maize rotation in the North China Plain. Agric. Water Manag. 2010, 97, 1139-1145. [CrossRef]

19. Djaman, K.; Irmak, S.; William, R.R.; Martin, D. Maize evapotranspiration, yield production functions, biomass, grain yield, harvest index, and yield response factors under full and limited irrigation. Trans. ASABE 2013, 56, 273-293. [CrossRef]

20. Qin, S.; Li, L.; Wang, D.; Zhang, J.L. Effects of Limited Supplemental Irrigation with Catchment Rainfall on Rain-fed Potato in Semi-arid Areas on the Western Loess Plateau, China. Am. J. Potato Res. 2013, 90, 33-42. [CrossRef]

21. Acharjee, T.K.; Halsema, G.; Ludwig, F.; Hellegers, P. Declining trends of water requirements of dry season Boro rice in the north-west Bangladesh. Agric. Water Manag. 2017, 180, 148-159. [CrossRef]

22. Kresovic, B.; Matovic, G.; Gregoric, E.; Djuricin, S.; Bodroza, D. Irrigation as a climate change impact mitigation measure: An agronomic and economic assessment of maize production in Serbia. Agric. Water Manag. 2014, 139, 7-16. [CrossRef]

23. Kresovi' ca, B.; Tapanarova, A.; Tomić, Z.; Zixotic, L. Grain yield and water use efficiency of maize as influenced by different irrigation regimes through sprinkler irrigation under temperate climate. Agric. Water Manag. 2016, 169, 34-43. [CrossRef]

24. Attia, A.; El-Hendawy, S.; Al-Suhaibani, N.; Alotaibi, M. Evaluating deficit irrigation scheduling strategies to improve yield and water productivity of maize in arid environment using simulation. Agric. Water Manag. 2021, 249, 106812. [CrossRef]

25. Djaman, K.; Irmak, S. Soil water extraction patterns and crop, irrigation, and evapotranspiration water use efficiency of maize under full and limited irrigation and rainfed settings. Trans. ASABE 2012, 55, 1223-1238. [CrossRef]

26. Zou, Y.F.; Saddique, Q.; Ajaz, A.; Xu, J.T. Deficit irrigation improves maize yield and water use efficiency in a semi-arid environment. Agric. Water Manag. 2020, 243, 106483. [CrossRef]

27. Heng, L.; Hsiao, T.C.; Evett, S.; Howell, T.A. Validating the FAO AquaCrop Model for Irrigated and Water Deficient Field Maize. Agron. J. 2009, 101, 488-498. [CrossRef]

28. Sandhu, R.; Irmak, S. Performance assessment of Hybrid-Maize model for rainfed, limited and full irrigation conditions. Agric. Water Manag. 2020, 242, 106402. [CrossRef] 
29. López-Urrea, R.; Domínguez, A.; Pardo, J.J.; Montoya, F. Parameterization and comparison of the AquaCrop and MOPECO models for a high-yielding barley cultivar under different irrigation levels. Agric. Water Manag. 2020, 230, 105931. [CrossRef]

30. Pirmoradian, N.; Davatgar, N. Simulating the effects of climatic fluctuations on rice irrigation water requirement using AquaCrop. Agric. Water Manag. 2019, 213, 97-106. [CrossRef]

31. Sandhu, R.; Irmak, S. Assessment of AquaCrop model in simulating maize canopy cover, soil-water, evapotranspiration, yield, and water productivity for different planting dates and densities under irrigated and rainfed conditions. Agric. Water Manag. 2019, 224, 105753. [CrossRef]

32. Bai, J.; Chen, X.; Dobermann, A.; Yang, H.S.; Kenneth, G.; Cassman, K.G.; Zhang, F.S. Evaluation of NASA Satellite and Model-Derived Weather Data for Simulation of Maize Yield Potential in China. Agron. J. 2010, 102, 9-16. [CrossRef]

33. Heilongjiang Bureau of Statistics. Heilongjiang Statistical Yearbook; China Statistics Press: Beijing, China, 2016. Available online: http:/ / tjj.hlj.gov.cn/tjsj/tjnj/ (accessed on 7 July 2021).

34. Wang, T.Y.; Du, C.; Nie, T.; Sun, Z.Y.; Liang, Q.Z. Spatiotemporal Analysis of Maize Water Requirement in the Heilongjiang Province of China during 1960-2015. Water 2020, 12, 2472. [CrossRef]

35. Heilongjiang Provincial Agriculture Committee. Division of Accumulated Temperature Zones of Crop Varieties in Heilongjiang Province. Available online: http/ / www.hljagri.gov.cn/nygk/nzwpzjwqh/ (accessed on 7 July 2021).

36. Accumulated Temperature Zone of Crop Varieties in Heilongjiang Province. Available online: http://www.hljagri.gov.cn/ (accessed on 7 July 2021).

37. Li, H. Experimental Study on Water Consumption Law and Irrigation Scheme Evaluation of Corn under Regulated Deficit Irrigation; Agricultural University: Harbin, China, 2016. (In Chinese)

38. Wang, D. Experimental Study on Coupling Effect of Water and Fertilizer of Corn Sprinkler Irrigation in Semi-Arid Area of Heilongiiang Province; Agricultural University: Harbin, China, 2016. (In Chinese)

39. Chen, S. Experimental Research on Corn Irrigation System and Water and Nitrogen Utilization in Semi-Arid Area of Western Heilongjiang; Northeast Agricultural University: Harbin, China, 2019. (In Chinese)

40. Bottazzi, M.; Bancheri, M.; Mobilia, M.; Bertoldi, G.; Rigon, R. Comparing Evapotranspiration Estimates from the GEOframeProspero Model with Penman-Monteith and Priestley-Taylor Approaches under Different Climate Conditions. Water 2020, 13, 1221. [CrossRef]

41. Zotarelli, L.; Dukes, M.D.; Romero, C.C.; Migliaccio, K.W.; Morgan, K.T. Step by Step Calculation of the Penman-Monteith Evapotranspiration (FAO-56 Method); Institute of Food and Agricultural Sciences, University of Florida: Gainesville, FL, USA, 2010; pp. 1-10.

42. Doorenbos, J.; Kassam, A.H. FAO Irrigation and Drainage Paper No. 33; FAO of UN: Rome, Italy, 1979; pp. 37-55. ISBN 925-10-0744-6.

43. Doorenbos, J.; Kassam, A.H. Yield Response to Water 1. Irrig. Agric. Dev. 1986, 33, 257-280. [CrossRef]

44. Steduto, P.; Hsiao, T.C.; Fereres, E. On the conservative behavior of biomass water productivity. Irrig. Sci. 2007, 25, 189-207. [CrossRef]

45. Steduto, P.; Hsiao, T.C.; Raes, D.; Fereres, E. AquaCrop-The FAO crop model to simulate yield response to water: I. Concepts and underlying principles. Agron. J. 2009, 101, 426-437. [CrossRef]

46. FAO. Crop yield response to water. In FAO Irrigation and Drainage Paper No. 66; Steduto, P., Hsiao, T.C., Raes, D., Eds.; FAO of UN: Rome, Italy, 2012; ISBN 978-92-5107274-5.

47. Kontoyiannis, H.; Jacovides, C.P. Statistical procedures for the evaluation of evapotranspiration computing models. Agric. Water Manag. 1995, 27, 365-371. [CrossRef]

48. Jamieson, P.D.; Porter, J.R.; Wilson, D.R. A test of the computer simulation model ARCWHEAT1 on wheat crops grown in New Zealand. Fields Crops Res. 1991, 27, 337-350. [CrossRef]

49. Nash, J.E.; Sutcliffe, J.V. River flow forecasting through conceptual models. J. Hydrol. 1970, 10, 282-290. [CrossRef]

50. Smith, M. CROPWAT: A Computer Program for Irrigation Planning and Management; FAO of UN: Rome, Italy, $1992 ;$ pp. 69-73. ISBN 92-5-103106-1.

51. Nie, T.; Zhang, Z.; Qi, Z.; Chen, P.; Sun, Z.; Liu, X.C. Characterizing Spatiotemporal Dynamics of $\mathrm{CH}_{4}$ Fluxes from Rice Paddies of Cold Region in Heilongjiang Province under Climate Change. Int. J. Environ. Res. Public Health 2019, 16, 692. [CrossRef] [PubMed]

52. Nie, T.Z.; Zhang, Z.; Lin, Y.; Chen, P.; Sun, Z. Spatial and Temporal Distribution Characteristics of Maize Water Requirement in Heilongjiang Province during 1959-2015. T Chin. Soc. Mach. 2018, 49, 218-227. (In Chinese)

53. Gao, X.; Wang, C.; Zhang, J.; Xue, X. Crop water requirement and temporal-spatial variation of drought and flood disaster during growth stages for maize in Northeast during past 50 years. Trans. CSAE 2012, 28, 101-109. (In Chinese)

54. Akhavan, S.; Kanani, E.; Dehghanisanij, H. Assessment of different reference evapotranspiration models to estimate the actual evapotranspiration of corn (Zea mays L.) in a semiarid region (case study, Karaj, Iran). Theor. Appl. Climatol. 2018, 137, 1403-1419. [CrossRef]

55. Sun, Y.; Gao, S.; Cao, Y.; Xu, J.Q.; Wang, Z. Study on the suitability of maize planting in Heilongjiang Province based on precipitation. J. Northeast Agric. Univ. 2017, 48, 33-41. (In Chinese)

56. Hu, X.; Chen, M.; Liu, D.; Li, D.; Luo, Y. Reference evapotranspiration change in Heilongjiang Province, China from 1951 to 2018 : The role of climate change and rice area expansion. Agric. Water Manag. 2021, 253, 106912. [CrossRef] 
57. Wang, Z.; Ye, A.; Wang, L.; Liu, K.; Cheng, L. Spatial and temporal characteristics of reference evapotranspiration and its climatic driving factors over China from 1979-2015. Agric. Water Manag. 2019, 213, 1096-1108. [CrossRef]

58. Irmak, S.; Djaman, K.; Rudnick, D.R. Effect of full and limited irrigation amount and frequency on subsurface drip-irrigated maize evapotranspiration, yield, water use efficiency and yield response factors. Irrig. Sci. 2016, 34, 271-286. [CrossRef] 